\title{
On the Electrocrystallization of Pure Hydroxyapatite Nanowalls on Nitinol Alloy Using a Bipolar Pulsed Current
}

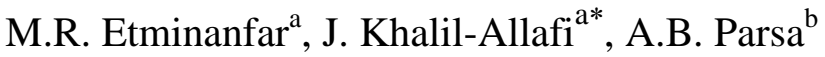 \\ ${ }^{a}$ Research Center for Advanced Materials, Faculty of Materials Engineering, Sahand University of \\ Technology, 5133511996, Tabriz, Iran. \\ ${ }^{\mathrm{b}}$ Institute of Materials Science, Ruhr-University Bochum, 150-44780, Bochum, Germany.
}

\begin{abstract}
In this study a bipolar pulsed current was used for the electrochemical deposition of calcium phosphate coatings on the Nitinol superelastic alloy. The coatings were characterized using FE-SEM, XRD, FTIR, HRTEM, and gas adsorption techniques. Results show that the electrodeposited coating is a crystalline film which is composed of pure hydroxyapatite (HA) nanowalls. According to the FTIR data, the coating is free from other metastable calcium phosphate phases like octacalcium phosphate. It was shown that both monoclinic and hexagonal phases can be detected in HRTEM images and related SAED patterns. The coating, which is deposited at direct and reverse current densities of -3.0 and $0.1 \mathrm{~mA} / \mathrm{cm}^{2}$ respectively, revealed a surface area of $38.5 \mathrm{~m}^{2} / \mathrm{g}$ and ultra-fine pores were detected in the surface of the coating plates. Study on the effect of the reverse pulse current revealed that the volume of porosity is increased by increasing in the current density of the reverse pulse. Also in this condition the resulted film was composed of nanosized HA crystals. It seems that the reverse current step can influence the porosity and the structure of the coatings by dissolution of the unstable phases which are formed during direct current step of the bipolar pulse deposition.
\end{abstract}

Keywords: Nitinol; Electrocrystallization; Hydroxyapatite; Monoclinic Phase; Bipolar Pulse Current.

* Corresponding author, Telefax.: +98 4133459454; E-mail address: allafi@ sut.ac.ir. 


\section{Introduction}

$\mathrm{NiTi}$ alloys have been considered as an important biomaterial since several years ago $[1,2]$. Metallic biomaterials which are used in human body should offer a reasonable biocompatibility especially in mechanical properties. In most other metallic implants, the elastic modulus mismatch between the implant and surrounding tissues restricts the life of implants [3]. The low difference between the elastic modulus of NiTi alloys and the human tissues makes the alloys a suitable candidate as implant materials [4].

Despite the superior properties of Nitinol alloys, there are some problems in the application of these alloys as implants especially because of the high Ni concentration and the bio inert surface of the alloy. It was shown that $\mathrm{Ni}$ ions leaching leads to a weak cells proliferation on the NiTi alloy [5, 6]. Also, the bio inert surface of the alloy leads to the formation of a bi-film on the implants which could be a reason for the failing of implantations [7-9].

Although Calcium-Phosphate (Ca-P) based compounds offer a good medium for the attachment and growth of living body cells, they cannot be used as bulk materials in implants due to their poor mechanical properties. Using Ca-P based coatings on the surface of metallic implants would be a suitable way to achieve the both advantages of metallic implants and CaP compounds [10, 11].

The Ca-P compounds generally include a wide range of structures with different $\mathrm{Ca} / \mathrm{P}$ stoichiometries. Hydroxyapatite (HA) is the most important calcium phosphate as the major mineral in hard tissues. It was shown that hydroxyapatite shows the best biocompatibility among other Ca-P compounds $[12,13]$. HA can crystallize in two forms of hexagonal and monoclinic. The hexagonal form of $\mathrm{HA}$ is the most regular structure which has lattice parameters of $a=b=9.4225(\AA), c=6.8850(\AA)$, and $\gamma=120^{\circ}[14]$. The monoclinic form of HA is the most ordered and the thermodynamically most stable form of HA. The major difference between the monoclinic and the hexagonal HA is the orientations of the hydroxyl groups. In 
the hexagonal phase, the hydroxyl groups place along the c-axis and the adjacent groups point in opposite directions. The hydroxide ions in the monoclinic phase are pointed in the same direction in a given column, and the direction reverses in the next column; accordingly the b-axis is doubled in comparison with that of the hexagonal phase [15]. Considering the similar electrical properties in bone and a synthetic monoclinic HA, the presence of monoclinic symmetry in biological apatite is predicted [16].

Different methods have been introduced for the precipitation of Ca-P compounds [17-21]. Electrocrystallization is one of the effective methods to deposit these compounds in low temperature with controlled thickness, crystallinity and morphology [21].

It was demonstrated that the unipolar pulsed current deposition gives more stable and crystalline Ca-P coatings as compared to the direct current deposition [21, 22]. Gopi et al. [21] studied the effects of a unipolar pulse deposition on the phase, composition, and morphology of Ca-P coatings on surgical grade stainless steel. It was proposed that the off part of the pulse cycle gives sufficient time for the diffusion of ions towards the substrate and favors HA formation. Wang et al. [23] used a bipolar pulsed current in the deposition of Ca-P film onto $\mathrm{Mg}-\mathrm{Zn}-\mathrm{Ca}$ alloy. The reverse current pulse with a high current density of 20 $\mathrm{mA} / \mathrm{cm}^{2}$ is applied to promote HA formation by dissolving $\mathrm{Mg}$ from the substrate. The resulted film is Ca-deficient apatite with a $\mathrm{Ca} / \mathrm{P}$ ratio of 1.3 .

While some contributions can be found in the literature on the synthesis of Ca-P compounds onto Nitinol alloys [24-26], pure HA film deposition by the pulse technique are not reported yet. Also, considering all published data on the electrolytic synthesis of HA, the phase analysis of HA and the monoclinic phase formation are not reported so far.

In the current work, a bipolar pulsed current was used for the synthesis of a pure HA film on Nitinol alloy. The crystal structure of the film was analyzed by XRD, selected area electron 
diffraction (SAED), as well as high resolution transmission electron microscopy (HRTEM). Also the gas adsorption analysis was used to investigate the porosity of coatings.

\section{Experimental details}

\subsection{Preparation of specimens}

In this work, NiTi rod with nominal composition of $50.9 \% \mathrm{Ni}$ was used to make substrates. The rods with the diameter of $13 \mathrm{~mm}$ were sliced into $1 \mathrm{~mm}$ disks. The surface of samples was abraded with different grades of SiC papers from P80 to P600 grit and then was etched in an acid solution of $1 \mathrm{HF}-4 \mathrm{NHO}_{3}-5 \mathrm{H}_{2} \mathrm{O}$ for 4 min, and finally was soaked in distilled boiling water for $20 \mathrm{~min}$. After each step, specimens were cleaned in acetone and then rinsed with deionized water. In order to age hardening of the bulk alloy and stabilizing the surface oxide film [27], the specimens were encapsulated in a glass tube after purging and vacuuming the high purity Ar gas inside the tubes for several times. The heat treatment carried out at $470{ }^{\circ} \mathrm{C}$ for $30 \mathrm{~min}$.

\subsection{Electrochemical deposition}

The electrodeposition was performed in an individual cell using a regular three electrode configuration in which NiTi alloy served as the cathode and a platinum mesh act as the anode. Along with this, saturated $\mathrm{Ag} / \mathrm{AgCl}$ electrode was used as the reference electrode. The distance between the anode and the cathode was fixed at $20 \mathrm{~mm}$. An electrolyte solution of $0.0084 \mathrm{M} \mathrm{Ca}\left(\mathrm{NO}_{3}\right)_{2} .4 \mathrm{H}_{2} \mathrm{O}, 0.005 \mathrm{M} \mathrm{NH}_{4} \mathrm{H}_{2} \mathrm{PO}_{4}, 0.1 \mathrm{M} \mathrm{NaNO}$, and $6 \mathrm{ml} / 1 \mathrm{H}_{2} \mathrm{O}_{2}$ was prepared and used for the electrodeposition. The $\mathrm{pH}$ of the electrolyte was adjusted to 6.0 by adding a Tris (hydroxymethyl aminomethane) solution and the temperature of the electrolyte was maintained at $65 \pm 1{ }^{\circ} \mathrm{C}$ using Bain-Marie method. The pulse deposition was carried out with the direct current $(\mathrm{ON})$ time of $1 \mathrm{~s}$ and the reverse current time of $2 \mathrm{~s}$. The direct pulse current 
density was $-3.0 \mathrm{~mA} / \mathrm{cm}^{2}$ and two values of 0.1 and $0.2 \mathrm{~mA} / \mathrm{cm}^{2}$ was used in the reverse pulse cycle. The deposited samples are labeled as $\mathrm{P}(-3,0.1)$ and $\mathrm{P}(-3,0.2)$ which the numbers show the direct and reverse current densities respectively. A high purity nitrogen gas was purged inside the electrolyte during the electrodeposition and mechanical stirring of the electrolyte was controlled at a speed of $150 \mathrm{rpm}$. The total deposition time was $25 \mathrm{~min}$ and the coatings thickness was $7 \pm 1 \mu \mathrm{m}$ which was measured from cross sectional images.

\subsection{Characterization of coatings}

For the electrodeposited film on Nitinol substrates, ATR-FTIR measurements were carried out on Bruker alpha (Germany) platinum ATR equipped with diamond crystal. The spectra were recorded between $400-4000 \mathrm{~cm}^{-1}$ by the resolution of $4.0 \mathrm{~cm}^{-1}$ and accumulation of 130 scan.

The structure of the calcium-phosphate based coatings was analyzed by X-ray diffraction (XRD) using BRUKER-D8 Advance-Germany Spectrometer, with $\mathrm{Cu}-\mathrm{K}_{\alpha}$ radiation generated at $40 \mathrm{kV}$ and $40 \mathrm{~mA}$. Data were collected over the $2 \theta$ range of $10-70^{\circ}$ with a step size of $0.04^{\circ}$ and a step time of $4 \mathrm{~s}$.

The surface morphology of the deposited films was examined by FEI-Quanta 400 FE6Netherland field emission SEM. The operating voltage in the microscope was $20.0 \mathrm{kV}$.

The $\mathrm{N}_{2}(77.4 \mathrm{~K})$ gas sorption measurements were carried out using a TriStar 3000 automated gas adsorption analyzer (micrometrics) in the relative pressure range, $\mathrm{P} / \mathrm{Po}$, from 0.01 to 0.99 atm. The saturated pressure was measured over 120 min intervals. The powder samples, which were obtained by scraping at least 50 coated samples, were degassed under a $\left(\sim 10^{-2}\right.$ Torr) for $3 \mathrm{~h}$ before the measurement.

The high resolution transmission electron microscopy (HRTEM) images were collected using Tecnai $\mathrm{G}^{2} \mathrm{~F} 20$ (USA) system, operating at $200 \mathrm{kV}$. For this purpose, the scraped samples 
were transferred to vials and absolute ethanol added. After ultrasonic operation, the welldispersed samples were drop-casted onto copper grids for TEM analysis.

\section{Results and discussion}

The surface morphology of $\mathrm{P}(-3,0.1)$ coating is depicted in Fig. 1. The coating is composed of ultrafine flakes and the thickness of the plates ranges between 10 and $90 \mathrm{~nm}$. It can be seen in Fig. 1 that there is almost a same growth direction normal to the cathode surface indicating the existence of the growth preference in the crystallization.

Fig. 2 shows the FTIR spectrum of the pulse deposited coating of $\mathrm{P}(-3,0.1)$. The absorbance bands of $\mathrm{PO}_{4}{ }^{3-}$ ions are depicted in the spectrum by $\mathrm{U}_{1}-\mathrm{U}_{4}$ stretching modes. It can be seen that there is no evidence for the presence of biphosphate group in the coating [28-30]. This result confirms that a pure hydroxyapatite film is deposited under the deposition condition and other Ca-P precursor phases such as octacalcium phosphate are completely converted to HA phase during the deposition. The carbonate absorbance bands $\left(\sim 870\right.$ and $\left.\sim 1400 \mathrm{~cm}^{-1}\right)$ could be originated from air carbonate or from the carbonate contaminations in the coating $[29,31]$.

It has been shown that the bipolar pulsed deposition modifies the concentration profile near the cathode surface by means of a step by step crystallization [32]. Fig. 3 shows a schematic representation of the proposed mechanism in the bipolar pulse deposition. Considering Fig. 3a, calcium ions could be adsorbed to the cathode surface during the direct current pulse. After the Ca ions adsorption, the polarity of the surface is going to be changed and some calcium-phosphates can be formed on the cathode by the reactions of calcium ions with phosphate groups that exist in the diffusion layer. Accordingly, different calcium phosphates could be formed on the cathode (Eq. 1-3). It has been reported that beside the hydroxyapatite 
that has a low water solubility, other calcium phosphate based compounds like octacalcium phosphate (OCP) and Brushite (dicalcium phosphate dehydrate, DCPD) can be dissolved in water based solutions [14, 33].

$$
\begin{aligned}
& \mathrm{Ca}^{2+}+\mathrm{HPO}_{4}^{2-}+2 \mathrm{H}_{2} \mathrm{O} \rightarrow \mathrm{CaHPO}_{4} \cdot 2 \mathrm{H}_{2} \mathrm{O} \quad(\mathrm{DCPD}) \\
& 8 \mathrm{Ca}^{2+}+2 \mathrm{HPO}_{4}^{2-}+4 \mathrm{PO}_{4}^{3-}+5 \mathrm{H}_{2} \mathrm{O} \rightarrow \mathrm{Ca}_{8} \mathrm{H}_{2}\left(\mathrm{PO}_{4}\right)_{6} \cdot 5 \mathrm{H}_{2} \mathrm{O} \quad(\mathrm{OCP}) \\
& 10 \mathrm{Ca}^{2+}+6 \mathrm{PO}_{4}^{3-}+2 \mathrm{OH}^{-} \rightarrow \mathrm{Ca}_{10}\left(\mathrm{PO}_{4}\right)_{6}(\mathrm{OH})_{2} \quad(\mathrm{HA})
\end{aligned}
$$

During the reverse current step, the sign of the double layer charge is changed and this results in desorption of hydrogen ions [32] and adsorption of hydroxyl groups to the surface (Fig. 3b). Consequently, biphosphate groups $\left(\mathrm{HPO}_{4}{ }^{2-}\right)$ could dissolve from the coating in the reverse cycle to produce $\mathrm{PO}_{4}{ }^{3-}$ ions through the reaction with hydroxyl groups (Eq. 4) [34]. It seems that the sequence of deposition and dissolution can favorite the formation of ordered and stable structures on the substrate.

$$
\mathrm{HPO}_{4}^{2-}+(\mathrm{OH})^{-} \rightarrow \mathrm{PO}_{4}^{3-}+\mathrm{H}_{2} \mathrm{O}
$$

In order to analyze the crystal structure of the coating, XRD analysis was carried out. Fig. 4 shows related XRD patterns of both $\mathrm{P}(-3,0.1)$ sample and the powder sample which was collected by scraping several coated samples of $\mathrm{P}(-3,0.1)$. According to the patterns, the coating shows HA specific peaks. It is well known that because of the structural similarity, the monoclinic and the hexagonal phases have extremely closed characteristic peaks which make it difficult to distinguish the structures by XRD measurements. Analyzing the phases by Rietveld method is only possible for well crystallized structures at elevated temperatures [15, 35] which is not the case in the current work.

Taking into account the peak intensities in Fig. 4, it is clear that the relative intensities of (002) and (004) peaks are higher in the coated sample when compared to the powder sample. Accordingly the film has a preferential growth on the Nitinol alloy along the c-axis. 
The high resolution TEM image of $\mathrm{P}(-3,0.1)$ sample is shown in Fig. 5. This image is taken perpendicular to one of the flakes of the coating. Two different kinds of atomic arrangement could be distinguished in Fig 5a which are marked with $\mathbf{A}$ and $\mathbf{B}$ circles. The SAED patterns related to each area are indexed in Fig. $5 \mathrm{~b}$ and $5 \mathrm{c}$. It can be seen that the atomic structure in the A marked area is related to the hexagonal HA and the zigzag atomic arrangement can be related to the monoclinic HA. In the diffraction patterns the zone axis of the monoclinic and the hexagonal phases are [110] and [1100] respectively. Ma et al. [35] have also reported the same atomic arrangement for the monoclinic and the hexagonal phases. It was shown that the difference in the atomic arrangement between the phases is basically related to the difference in hydroxyl ions positioning.

It is well known that an intermixture of hexagonal and monoclinic HA would not alter the pattern as the spots from the hexagonal HA would be contained within the monoclinic structure [35]. Due to coexistence of the monoclinic and hexagonal phases all over the flake (Fig. 5a), weak spots related to the adjacent area of the other phase can be distinguished in both diffraction patterns.

It has been reported that monoclinic phase is the most ordered and structurally stable form of HA. Based on the theoretical results, the monoclinic phase of HA energetically is more favorable phase than the hexagonal one [36]. On the other hand, considering the kinetic factor, the formation of hexagonal phase in ordinary conditions is more favorable compared to the monoclinic phase. Some parameters like high temperature and high $\mathrm{pH}$ can promote the monoclinic phase formation $[37,38]$. On the other hand, supplying an insufficient amount of hydroxyl groups during the deposition can result in disturbing the order of hydroxyl groups and the resulted deposit would be the hexagonal phase [15]. The proposed mechanism in Fig. 3 could be taken into account to explain the presence of the monoclinic phase in the coating. 
It seems that the adsorption of hydroxide ions to the surface during applying the reverse current promotes the possibility of the monoclinic phase formation.

The gas adsorption method was used to analyze the pore sizes, pore volume, and pore size distribution in the scraped powder samples of the HA coating. Fig. 6 shows the $\mathrm{N}_{2}$ sorption isotherm and pore size distribution plot for $\mathrm{P}(-3,0.1)$ sample. It can be easily seen that the isotherms shows the characteristic of mesoporous materials. The obtained values from BET analysis are listed in Table 1.

Although the plate like morphologies demonstrate a hysteresis in the gas adsorption curve, the apparent surface area which are seen in Fig. 1 and the pores between flakes could not solely account for such a large surface area.

Fig. 7 shows a bright field TEM image from the scraped sample. It can be seen that the surface contains nanosized pores that are distributed uniformly on the surface. It has been reported that gas bubbles during electrodeposition can result in the mesoporous film formation [39]. Beside this effect, as seen in marked areas of Fig. 7, it seems that these holes are produced as a result of the coating dissolution. Accordingly, the proposed mechanism in the dissolution of coatings during the reverse pulse could be taken into account as a source of pore generation in the coatings.

To evaluate the role of the reverse pulse on the porosity of the coatings, the reverse current density of $0.2 \mathrm{~mA} / \mathrm{cm}^{2}$ was also examined. The FESEM micrographs of the $\mathrm{P}(-3,0.2)$ sample are depicted in Fig. 8. Although the coating has a nanowall morphology same as the $\mathrm{P}(-3,0.1)$ sample, under a visual observation the uniformity of the $\mathrm{P}(-3,0.2)$ sample was not as good as the previous one. Comparing Fig. 1a and 8 reveals that the uniformity of the crystal growth at the lower reverse current density of $0.1 \mathrm{~mA} / \mathrm{cm}^{2}$ is higher than that of the higher reverse current density of $0.2 \mathrm{~mA} / \mathrm{cm}^{2}$. 
Fig. 9 shows the $\mathrm{N}_{2}$ sorption isotherm and the pore size distribution for the $\mathrm{P}(-3,0.2)$ sample. The obtained values from BET analysis are listed in Table 1. Comparing the porosity of two different pulse deposition conditions reveals that by increasing the reverse pulse current, the pore volume is increased. This observation can confirm the effect of the reverse pulse on the dissolution of coatings which discussed earlier.

Table 1- The BET analysis results of the HA coatings electrodeposited at different reverse current densities.

\begin{tabular}{ccc}
\hline Parameters\Reverse current density $\left(\mathbf{m A} / \mathbf{c m}^{2}\right)$ & $\mathbf{0 . 1}$ & $\mathbf{0 . 2}$ \\
\hline BET Surface Area $\left(\mathbf{m}^{2} / \mathbf{g}\right)$ & 38.47 & 48.31 \\
BJH Desorption Surface Area $\left(\mathbf{m}^{\mathbf{2}} / \mathbf{g}\right)$ & 62.68 & 83.17 \\
BJH Pore Volume $\left(\mathbf{c m}^{\mathbf{3}} / \mathbf{g}\right)$ & 0.170 & 0.212 \\
\hline
\end{tabular}

Fig. 10a shows TEM image of the $\mathrm{P}(-3,0.2)$ coating which indicates the mesoporous structure in the film. According to the SAED pattern (Fig. 10b), the reverse pulse have also influenced the grain size of the coating. The ring pattern is related to the [111] zone axis of HA phase. It seems that, dissolution of the coating in the reverse current step is high enough for overall structural changes in the coating and the final deposit is composed of ultrafine grains of hydroxyapatite.

\section{Conclusion:}

Based on the results of this work, the bipolar pulse electrodeposition at $65{ }^{\circ} \mathrm{C}$ can successfully produce a pure HA film on the Nitinol alloy which shows uniform nanowall morphology. It was shown that both monoclinic and hexagonal phases can be detected in HRTEM images and related SAED patterns. The crystallized HA plates show a mesoporous structure as a result of the coating dissolution during the reverse pulse. The pores volume is 
increased by increasing in the reverse pulse current density and this is accompanied by decreasing in the uniformity of the coating. Also in this condition the resulted film is composed of ultrafine grained HA crystals.

\section{Acknowledgements:}

The authors would like to acknowledge the financial support of Iran National Science Foundation (INSF) under the contract No. 92004023. Also the authors acknowledge Prof. Ö. Dag from Bilkent University, Turkey for FTIR and the gas adsorption analysis.

\section{References:}

[1] A.R. Pelton, D. Stockel, T.W. Duerig, Medical Uses of Nitinol, Mater. Sci. Forum. 327 (2000) 63-70.

[2] M.H. Elahinia, M. Hashemi, M. Tabesh, S.B. Bhaduri, Manufacturing and processing of NiTi implants, Prog. Mater. Sci. 57 (2012) 911-946.

[3] J. Nagels, M. Stokdijk, P. M. Rozing, Stress shielding and bone resorption in shoulder arthroplasty, J. Shoulder Elbow Surg. 12 (2003) 35-39.

[4] B. V. Krishna, S. Bose, A. Bandyopadhyay, Laser processing of net-shape NiTi shape memory alloy, Metall. Mater. Trans. A. 38 (2007) 1096-1103.

[5] J. Khalil-Allafi, B. Amin-Ahmadi, M. Zare, Biocompatibility and corrosion behavior of the shape memory NiTi alloy in the physiological environments simulated with body fluids for medical applications, Mater. Sci. Eng. C 30 (2010) 1112-1117.

[6] E. Czarnobilska, K. Obtułowicz, K. Wsołek, J. Piętowska, R. Śpiewak, Mechanizmy alergii na nikiel, Przegl. Lek. 64 (2007) 502-505. 
[7] A. Runciman, D. Xu, A. R. Pelton, R. O. Ritchie, An equivalent strain/CoffinManson approach to multiaxial fatigue and life prediction in superelastic Nitinol medical devices, Biomaterials 32 (2011) 4987-4993.

[8] M. Geetha, A. Singh, R. Asokamani, A. Gogia, Ti based biomaterials, the ultimate choice for orthopaedic implants-a review, Prog. Mater. Sci. 54 (2009) 397-425.

[9] F. Silver. Biomaterials, Medical Devices and Tissue Engineering: An Integrated Approach, Springer, London, 1994.

[10] Ch.K. Lee, Fabrication, characterization and wear corrosion testing of bioactive hydroxyapatite/nano- $\mathrm{TiO}_{2}$ composite coatings on anodic $\mathrm{Ti}-6 \mathrm{Al}-4 \mathrm{~V}$ substrate for biomedical applications, Mater. Sci. Eng. B 177 (2012) 810-818.

[11] J. Katic, M. Metikos-Hukovi, S.D. Skapin, M. Petravic, M. Varasanec, The potentialassisted deposition as valuable tool for producing functional apatite coatings on metallic materials, Electrochim. Acta. 127 (2014) 173-179.

[12] S. Best, B. Sim, M. Kayser, S.Downes, The dependence of osteoblastic response on variations in the chemical composition and physical properties of hydroxyapatite, J. Mater. Sci. Mater. Med. 8 (1997) 97-103.

[13] M.R. Etminanfar, J. Khalil-Allafi, A. Montaseri, R. Vatankhah-Barenji, Endothelialization and the bioactivity of $\mathrm{Ca}-\mathrm{P}$ coatings of different $\mathrm{Ca} / \mathrm{P}$ stoichiometry electrodeposited on the Nitinol superelastic alloy, Mater. Sci. Eng. C 62 (2016) $28-35$.

[14] J.C. Elliott, Structure and chemistry of the apatites and other calcium orthophosphates. Elsevier, Amsterdam, 1994.

[15] H. Morgan, R.M. Wilson, J.C. Elliott, S.E.P. Dowker, P. Anderson, Preparation and characterisation of monoclinic hydroxyapatite and its precipitated carbonate apatite intermediate, Biomaterials 21 (2000) 617-627 
[16] M. Espanol, J. Portillo, J.M. Manero, M.P. Ginebra, Investigation of the hydroxyapatite obtained as hydrolysis product of a-tricalcium phosphate by transmission electron microscopy, Cryst. Eng. Comm. 12 (2010) 3318-3326.

[17] E. Karimi, J. Khalil-Allafi, V. Khalili, Electrophoretic deposition of double-layer HA/Al composite coating on NiTi, Mater. Sci. Eng. C 58 (2016) 882-890.

[18] S. Durdu, Ö.F. Deniz, I. Kutbay, M. Usta, Characterization and formation of hydroxyapatite on $\mathrm{Ti}_{6} \mathrm{Al}_{4} \mathrm{~V}$ coated by plasma electrolytic oxidation, J. Alloys Compd. 551 (2013) 422-429.

[19] J.X. Zhang, R.F. Guan, X.P. Zhang, Synthesis and characterization of sol-gel hydroxyapatite coatings deposited on porous NiTi alloys, J. Alloys Compd. 509(13) (2011) 4643-4648.

[20] M. Ren, S. Cai, T. Liu, K. Huang, X. Wang, H. Zhao, S. Niu, R. Zhang, X. Wu, Calcium phosphate glass/ $\mathrm{MgF}_{2}$ double layered composite coating for improving the corrosion resistance of magnesium alloy, J. Alloys Compd. 591 (2014) 34-40.

[21] D. Gopi, J. Indira, L. Kavitha, A comparative study on the direct and pulsed current electrodeposition of hydroxyapatite coatings on surgical grade stainless steel, Surf. Coat. Technol. 206 (2012) 2859-2869.

[22] D.J. Blackwood, K.H.W. Seah, Galvanostatic pulse deposition of hydroxyapatite for adhesion to titanium for biomedical purposes, Mater. Sci. Eng. C 30(4) (2010) 561-565. [23] H. Wang, S. Zhu, L. Wang, Y. Feng, X. Ma, S. Guan, Formation mechanism of Cadeficient hydroxyapatite coating on $\mathrm{Mg}-\mathrm{Zn}-\mathrm{Ca}$ alloy for orthopaedic implant, Appl. Surf. Sci. 307 (2014) 92-100.

[24] J. Katić, M. Metikoš-Huković, R. Babić, Synthesis and characterization of calcium phosphate coatings on Nitinol", J. Appl. Electrochem. 44(1) (2014) 87-96. 
[25] A.O. Lobo, J. Otubo, J.T. Matsushima, E.J. Corat, Rapid Obtaining of NanoHydroxyapatite Bioactive Films on NiTi Shape Memory Alloy by Electrodeposition Process, J. Mater. Eng. Perform. 20 (2011) 793-797.

[26] D. Qiu, L. Yang, Y. Yin, A. Wang, Preparation and characterization of hydroxyapatite/titania composite coating on NiTi alloy by electrochemical deposition, Surf. Coat. Technol. 205 (2011) 3280-3284.

[27] M.R. Etminanfar, J. Khalil-Allafi, On the Electrodeposition of Ca-P Coatings on Nitinol Alloy: A Comparison between Different Surface Modification Methods, J. Mater. Eng. Perform. 25 (2016) 466-473.

[28] L. Chetibi, D. Hamana, S. Achour, Growth and characterization of hydroxyapatite nanorice on TiO2 nano fibers, Mater. Chem. Phys. 144 (2014) 301-309.

[29] R. Hu, Ch.J. Lin, H.Y. Shi, A novel ordered nano hydroxyapatite coating electrochemically deposited on titanium substrate, J. Biomed. Mater. Res. 80A (2007) $687-692$.

[30] M. Shirkhanzadeh, Direct formation of nanophase hydroxyapatite on cathodically polarized electrodes, J. Mater. Sci. Mater. Med. 9(2) (1998) 67-72.

[31] D.T.M. Thanh, P.T. Nam, N.T. Phuong, L.X. Que, N.V. Anh, T. Hoang, T.D. Lam, Controlling the electrodeposition, morphology and structure of hydroxyapatite coating on 316L stainless steel, Mater. Sci. Eng. C 33 (2013) 2037-2045.

[32] D. Landolt, A. Marlot, Microstructure and composition of pulse-plated metals and alloys, Surf. Coat. Technol. $169-170$ (2003) 8-13.

[33] S. Takagi, L.C. Chow, K. Ishikawa, Formation of hydroxyapatite in new calcium phosphate cements, Biomaterials 19 (1998) 1593-1599. 
[34] N. Eliaz, M. Eliyahu, Electrochemical processes of nucleation and growth of hydroxyapatite on titanium supported by real-time electrochemical atomic force microscopy. J. Biomed. Mat. Res. A, 80(3) (2007) 621-634.

[35] G. Ma and X. Y. Liu, Hydroxyapatite: Hexagonal or Monoclinic? Cryst. Growth Des. 9 (2009) 2991-2994.

[36] D. Haverty, S.A.M. Tofail, K.T. Stanton, J. B. McMonagle, Structure and stability of hydroxyapatite: Density functional calculation and Rietveld analysis, Phys. Rev. B 71 (2005) 94103-94109.

[37] T. Ikoma, A. Yamazaki, S. Nakamura and M. Akao, Preparation and Structure Refinement of Monoclinic Hydroxyapatite, J. Solid State Chem. 144 (1999) 272-276. [38] O. Hochrein, R. Kniep, D. Zahn, Atomistic Simulation Study of the Order/Disorder (Monoclinic to Hexagonal) Phase Transition of Hydroxyapatite, Chem. Mater. 17 (2005) 1978-1981.

[39] D. Liu, B.B. Garcia, Q. Zhang, Q. Guo, Y. Zhang, S. Sepehri, G. Cao, Mesoporous Hydrous Manganese Dioxide Nanowall Arrays with Large Lithium Ion Energy Storage Capacities, Adv. Funct. Mater. 19 (2009) 1015-1023. 


\section{Figure captions:}

Fig. 1- (a) to (c) FE-SEM micrographs of the pulse deposited sample under direct and reverse pulse current densities of -3 and $0.1 \mathrm{~mA} / \mathrm{cm}^{2}$ respectively.

Fig.2- FTIR spectrum of the pulse deposited sample under direct and reverse pulse current densities of -3 and $0.1 \mathrm{~mA} / \mathrm{cm}^{2}$ respectively.

Fig. 3- Schematic representation of the proposed mechanism in the pulsed deposition during applying (a) the direct current pulse, and (b) the reverse current pulse.

Fig. 4- XRD patterns of (a) $\mathrm{P}(-3,0.1)$ coating, and (b) scraped powder of several coated samples under direct and reverse pulse current densities of -3 and $0.1 \mathrm{~mA} / \mathrm{cm}^{2}$ respectively.

Fig. 5- (a) HRTEM image of the pulse deposited sample of $\mathrm{P}(-3,0.1)$, (b) and (c) SAED patterns of $\mathbf{A}$ and $\mathbf{B}$ marked area respectively.

Fig. 6- (a) 77.4 $\mathrm{K} \mathrm{N}_{2}$-Sorption Isotherms, (b) Pore size distribution plot of the pulse deposited Ca-P coating under direct and reverse current densities of -3 and $0.1 \mathrm{~mA} / \mathrm{cm}^{2}$ respectively.

Fig. 7- The bright field TEM image of the pulse deposited Ca-P coating under direct and reverse pulse current densities of -3 and $0.1 \mathrm{~mA} / \mathrm{cm}^{2}$ respectively.

Fig. 8- FE-SEM micrographs of the pulse deposited sample at the direct and the reverse pulse current densities of -3 and $0.2 \mathrm{~mA} / \mathrm{cm}^{2}$ respectively.

Fig. 9- (a) 77.4 $\mathrm{K} \mathrm{N}_{2}$-Sorption Isotherms, (b) Pore size distribution plot of the pulse deposited Ca-P coating under direct and reverse pulse current densities of -3 and $0.2 \mathrm{~mA} / \mathrm{cm}^{2}$ respectively. 
Fig. 10- (a) The bright field TEM image and (b) SAED pattern of the pulse deposited Ca-P coating under direct and reverse current densities of -3 and $0.2 \mathrm{~mA} / \mathrm{cm}^{2}$ respectively. 


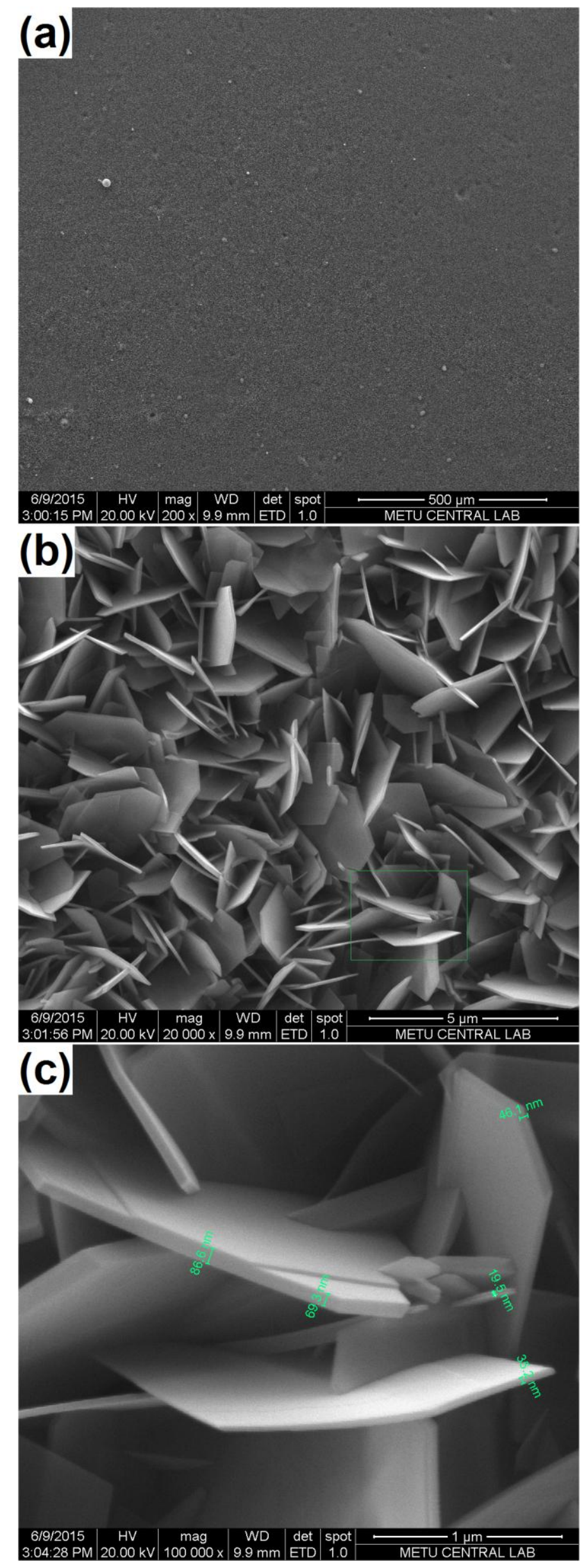




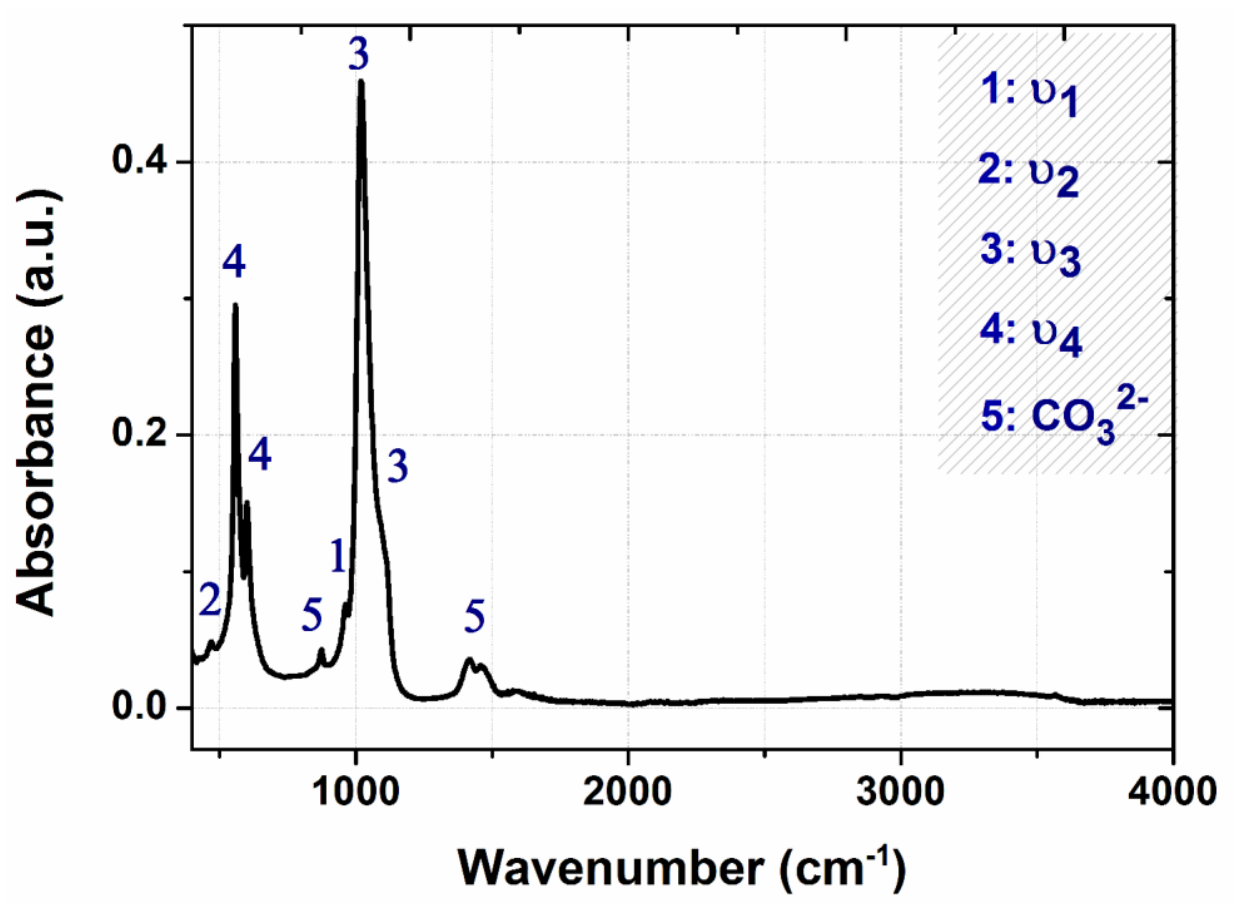




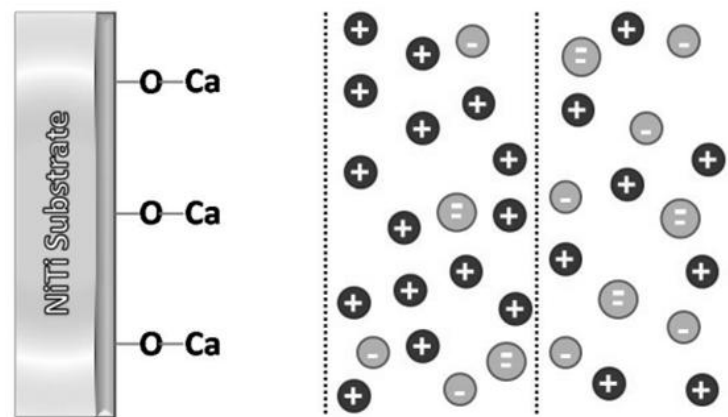

(a) $\odot \mathrm{HPO}_{4}{ }^{2-} \quad \odot \mathrm{OH}^{-} \quad \oplus \mathrm{Ca}^{2+}$

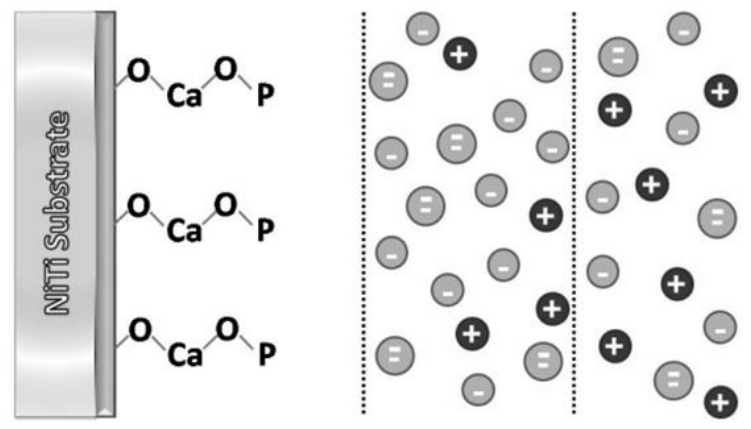

(b) $\odot \mathrm{HPO}_{4}{ }^{2-} \quad \odot \mathrm{OH}^{-} \quad \odot \mathrm{Ca}^{2+}$ 

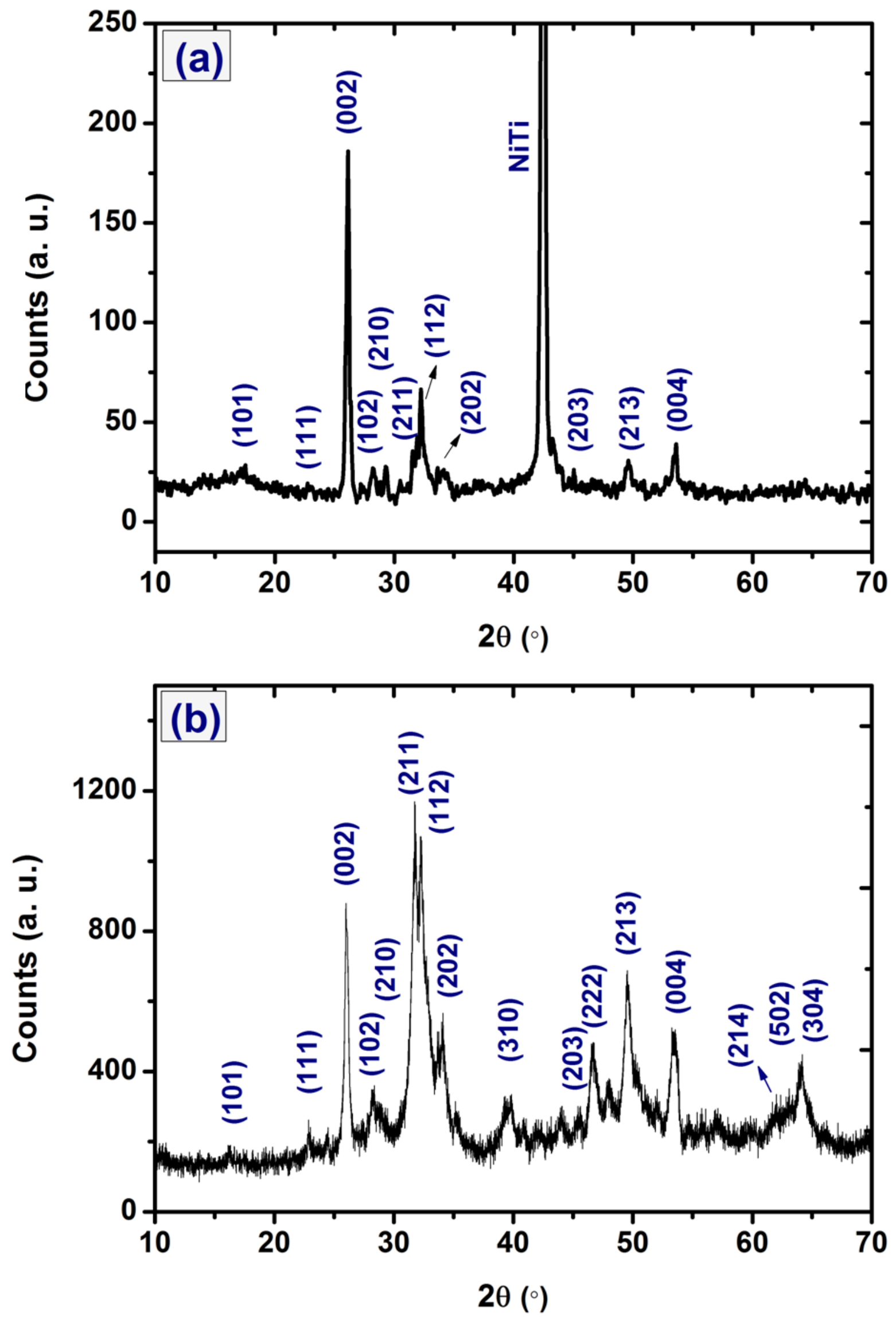


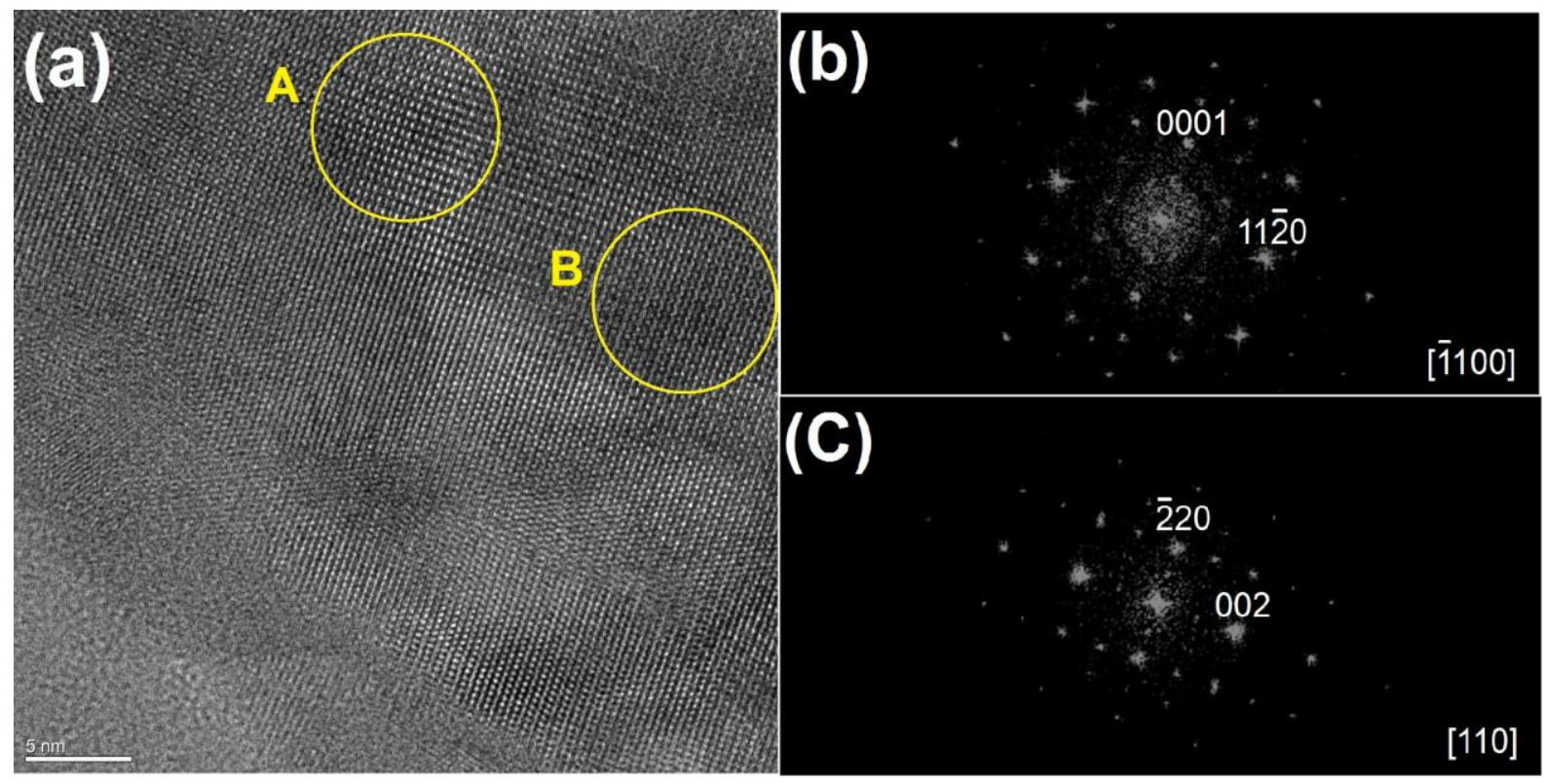




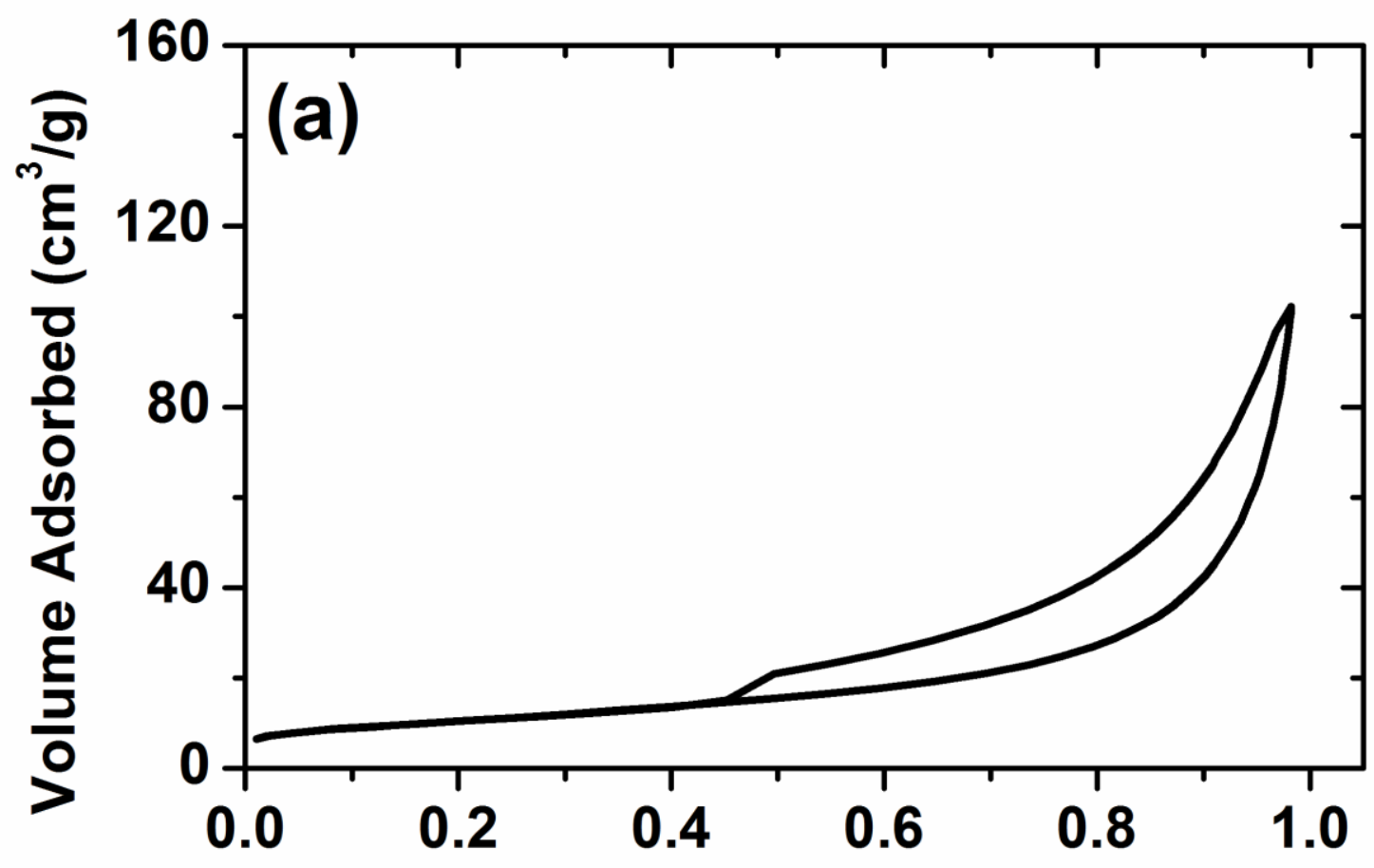

Relative Pressure (P/Po)

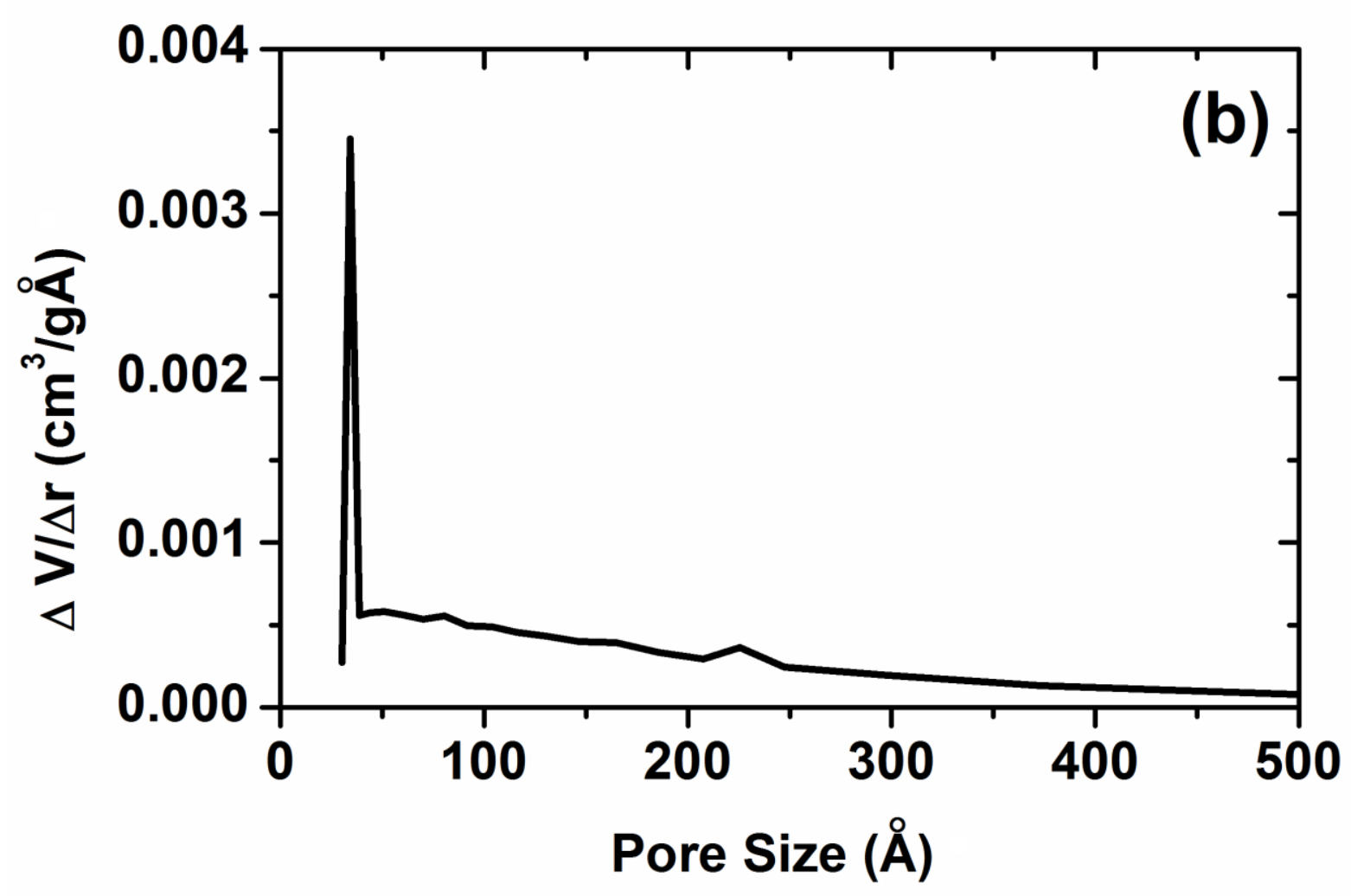




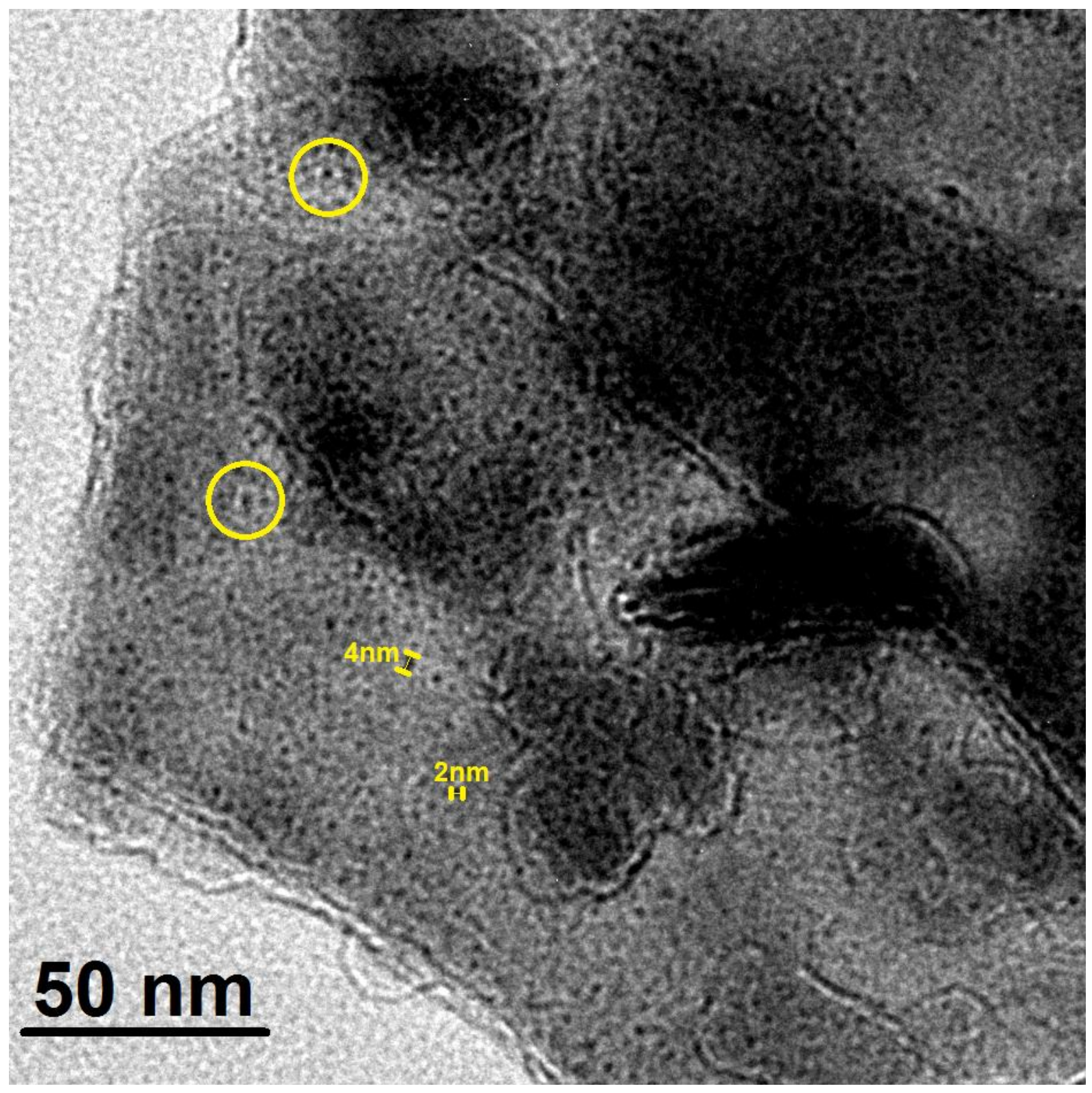




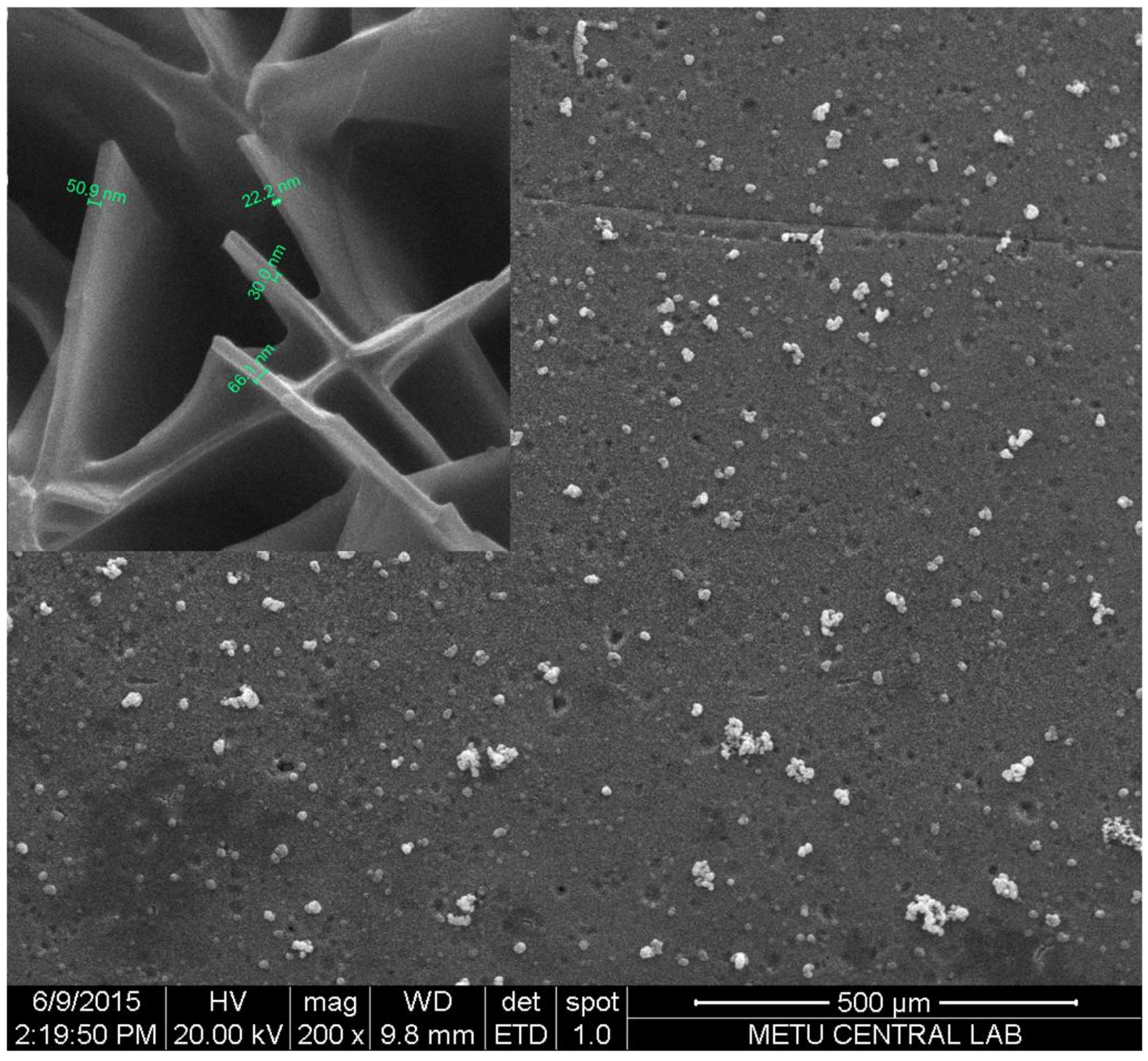




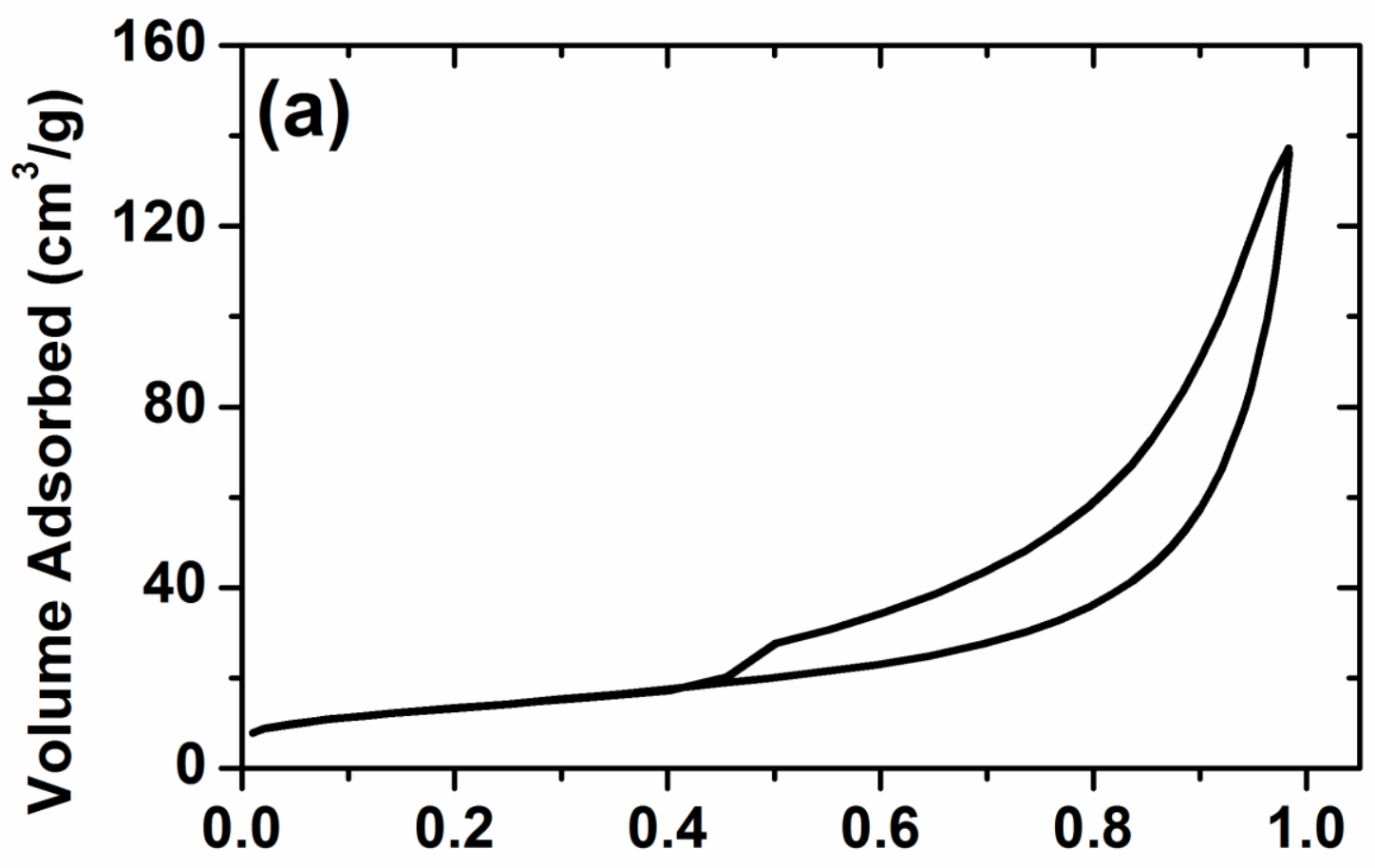

Relative Pressure (P/Po)

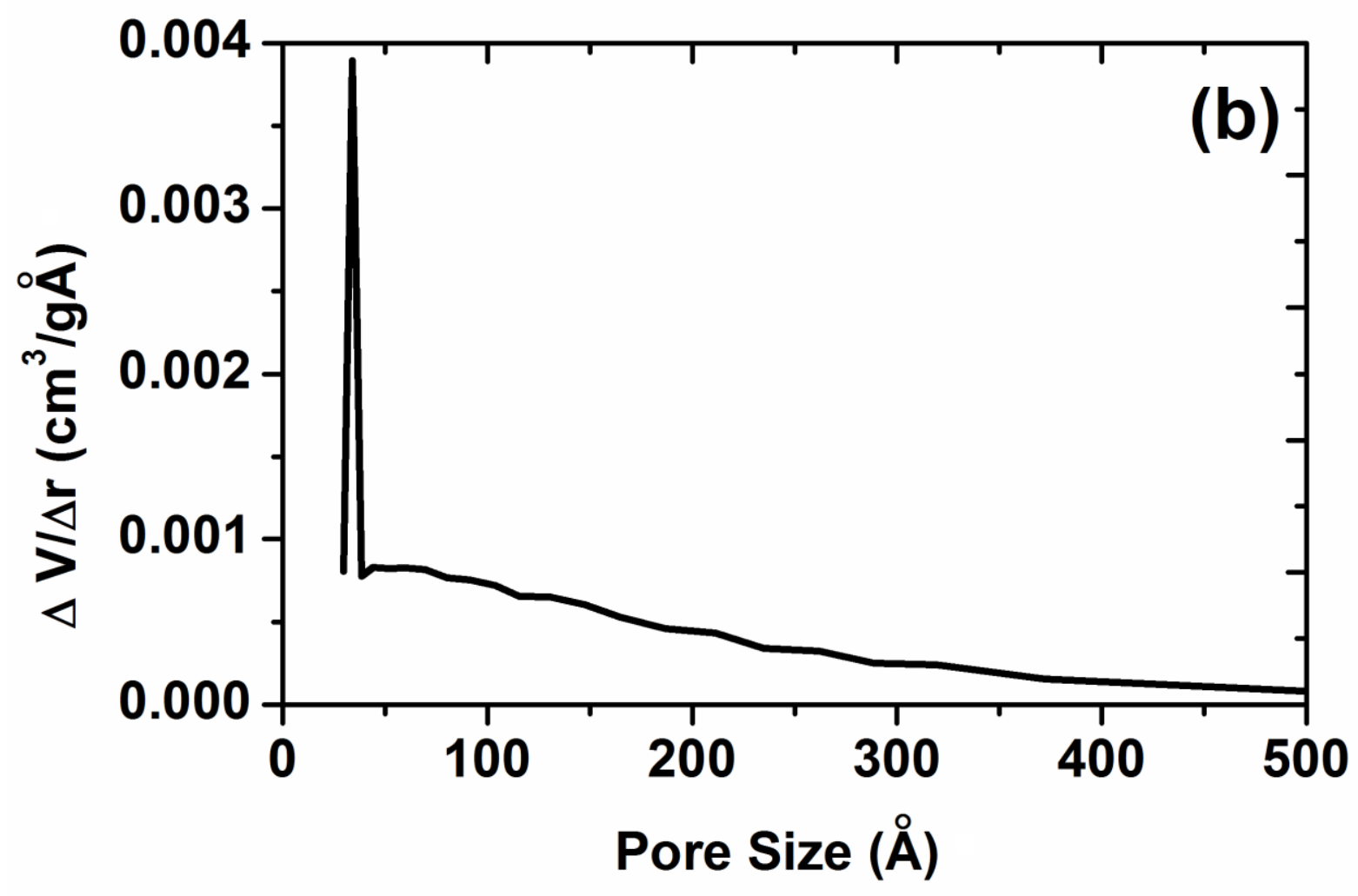


(a)

$4 \mathrm{~nm}$

(112) _ - (101)

7 nn (011)

(b) 